\title{
Enhanced Urban Path Loss Prediction Model with New Correction Factors
}

\author{
Do-Young KWAK ${ }^{\dagger}$, Chang-Hoon LEE ${ }^{\dagger}$, Nonmembers, Seong-Cheol KIM ${ }^{\dagger a}{ }^{\text {a) }}$ Member, Jae-Woo LIM ${ }^{\dagger \dagger}$, \\ and Sung-Soo LEE ${ }^{\dagger \dagger}$, Nonmembers
}

\begin{abstract}
SUMMARY Modification of ITU-R P.1411 model to enhance the prediction accuracy in urban environments having variable heights of buildings is proposed in this paper by introducing two kinds of novel correction factors. One is considering the relationship of the highest building height and the transmitter (Tx) antenna height, and the other is considering the effect of receiver $(\mathrm{Rx})$ position on crossroads. After introducing two correction factors, the prediction accuracy is shown to be improved.

key words: correction factors, path loss prediction, ITU-R P.1411 model, urban environment
\end{abstract}

\section{Introduction}

Recently, most channel models are describing wide-band channel characteristics for the high data rate wireless transmission. But the narrow-band channel model, such as path loss model is still important for the deployment strategy of wireless communication service and the analysis of interferences. Okumura-Hata [1], [2], COST231-hata [3] and COST231-WI [3] models are known as representative narrowband models. However ITU-R P.1546 [4] and ITU-R P.1411 [5] models recently modified to include the properties of these existing models.

Although these models are widely used, the models provide relatively accurate results only for simple environment. Some prediction errors are observed for actual urban environment because the heights of buildings are not so uniform. In this paper, new correction factors for ITU-R P.1411 model are suggested, which results in the considerable improvement of prediction accuracy.

\section{Measurement Campaign}

The continuous wave (CW) propagation loss measurements campaign and its prediction based on the path loss model at $2.17 \mathrm{GHz}$ were carried out for two types of urban environments (Yeouid-do and Gangnam, two typical urban environments of Seoul, Korea). In the urban type I (Yeoui-do area), low buildings and high-rise buildings are mixed along boulevards and the average building height is $34 \mathrm{~m}$. On

\footnotetext{
Manuscript received August 22, 2005.

Manuscript revised October 18, 2005.

${ }^{\dagger}$ The authors are with Institute of New Media and Communications, Seoul National Univeristy, Korea.

${ }^{\dagger}$ The author is with Radio Research Laboratory, Korea.

$t^{\dagger \dagger}$ The author is with Radio and Broadcasting Laboratory, Electronics and Telecommunications Research Institute, Korea.

a)E-mail: sckim@maxwell.snu.au.kr

DOI: 10.1093/ietcom/e89-b.4.1459
}

the other hand, high-rise buildings are mostly located along boulevards while low buildings are located behind high-rise buildings in the urban type II (Gangnam area). The average building height is $12.2 \mathrm{~m}$ in the urban type II but about 440 buildings (about $5 \%$ of the total buildings) are higher than $30 \mathrm{~m}$ and about $90 \%$ of the total buildings are lower than $20 \mathrm{~m}$. The street shapes of both environments are close to rectangular grids. The measured area for each environment was about $2 \mathrm{~km} \times 2 \mathrm{~km}$ with transmitter (Tx) antenna as its center.

The Tx antennas were located on the top of building with heights of $48.7 \mathrm{~m}$ for Yeoui-do area and $54 \mathrm{~m}$ for Gangnam area. The receiving antenna was mounted on the top of the measurement van at the height of $2.6 \mathrm{~m}$ from the ground. Omni-directional antennas were used for both Tx and Rx. The input power to the transmitting antenna was fixed at $30 \mathrm{dBm}$. The measurement van moved at the speed of about $15 \mathrm{~km} / \mathrm{hr}$ along street and the speed was slower than that depending on the traffic condition while signal strengths were recorded at the rate of a sample per a second.

The instantaneous CW power was obtained during measurement, but the local mean $\hat{m}(x)$ is calculated to compare with predictions using following equation [6], which is denoted as "running means":

$$
\hat{m}(x)=\frac{1}{2 L} \int_{x-L}^{x+L} r(y) d y
$$

where $r(y)$ is the envelope of the signal, $2 L$ the window length, respectively. In this study, the length $2 L$ is chosen as $80 \lambda(\sim 11.6 \mathrm{~m})$ to obtain the true local mean, which leads more than 3 samples to be included in computing the local mean.

\section{Application of Existing Model}

Generally, path loss is modeled as the sum of the free space path loss $L_{b f}$, the excess loss $L_{e x, 1}$ due to terrain variation, $L_{e x, 2}$ due to buildings and trees and gain $G$ due to antenna heights as follows:

$$
L=L_{b f}+L_{e x, 1}+L_{e x, 2}+G\left(h_{b,} h_{m}\right)
$$

where $h_{b}$ and $h_{m}$ are Tx and Rx antenna heights, respectively. Propagation along paths less than $1 \mathrm{~km}$ in urban is known to be affected primarily by buildings and trees rather than by terrain variation [5]. ITU-R P.1411 model is proper 
to describe path loss along short distances at the urban environment since it carefully considers the effects of buildings, street and antenna heights by $L_{e x, 2}$.

The measurement frequency is outside of the range of the applicable frequency range of ITU-R P.1411 model $(800 \mathrm{MHz}-2 \mathrm{GHz})$. But the frequency difference of a few hundreds $\mathrm{MHz}$ at high frequency band results in small path loss difference as reported in the literature [7]. Therefore the measurement results at $2.17 \mathrm{GHz}$ are also valid for comparison with the prediction results.

In this study, Tx antennas are on the top of building but there rarely exist line of sight (LoS) paths between Tx and Rxs. Therefore, NLoS ITU-R P.1411 model for propagation over rooftops could be applied and modified. The model is expressed as the sum of $L_{b f}$, the diffraction loss over roof-top of last building to street $\left(L_{r t s}\right)$ and the loss due to multiple diffractions past rows of buildings $\left(L_{m s d}\right)$ as follows:

$$
\begin{aligned}
& L_{N L o S, 1}=\left\{\begin{array}{cc}
L_{b f}+L_{r t s}+L_{m s d}, & L_{r t s}+L_{m s d}>0 \\
L_{b f}, & L_{r t s}+L_{m s d} \leq 0
\end{array}\right. \\
& L_{b f}=f\left(d, f_{c}\right), L_{r t s}=f\left(w, \varphi, h_{r}, h_{m}, f_{c}\right) \\
& L_{m s d}=f\left(h_{r}, h_{b}, d, f_{c}, b\right)
\end{aligned}
$$

In Eq. (3), $d$ is distance between $\mathrm{Tx}$ and $\mathrm{Rx}, f_{c}$ carrier frequency, $w$ street width, $\varphi$ street orientation with respect to the direct path, $h_{r}$ the average height of buildings, and $b$ the average building separation, respectively.

In order to consider the variable heights of the buildings between $\mathrm{Tx}$ and $\mathrm{Rx}$, the ITU-R P.1411 model recommended that it is preferred to replace the excess loss $\left(L_{r t s}+L_{m s d}\right)$ by the knife-edge diffraction loss $L_{k e}$. In other words, when building height differences vary by much more than the 1 st Fresnel zone radius over a path of length $l$, the path loss is expressed as the sum of $L_{b f}$ and $L_{k e}$ due to the highest building as follows [8]:

$$
\begin{aligned}
& L_{N L o s, 2}=L_{b f}+L_{k e} \\
& L_{k e}=f\left(h, \lambda, d_{1}, d_{2}\right)
\end{aligned}
$$

where $l$ denotes the length of the path covered by buildings between Tx and Rx. And $h$ is the height of the top of the highest building above the straight line joining the Tx and Rx points, $\lambda$ the wavelength of the carrier frequency, $d_{1}$ and $d_{2}$ the distance from Tx to the highest building and from the highest building to $\mathrm{Rx}$, respectively. The radius of the 1 st Fresnel ellipsoid at a point between $A$ and $B$ is given as follows [8]:

$$
R_{1}=\sqrt{\frac{\lambda d_{a} d_{b}}{d_{a}+d_{b}}}
$$

where $d_{a}$ and $d_{b}$ are the distance from $A$ to a point and from a point to $B$, respectively.

Therefore the mixed predicted path loss is expressed as follows:

$$
L_{N L o S, 3}= \begin{cases}L_{N L o S, 1}, & h_{\max } \leq h_{r}+R_{1, \max } \\ L_{N L o S, 2}, & \text { else }\end{cases}
$$

where $h_{\max }$ is the height of the highest building in the buildings existing along the direct path of Tx-Rx pair and $R_{1, \max }$ the 1 st Fresnel ellipsoid radius at the location of the highest building, respectively.

The existing ITU-R P.1411 model is applied to predict path loss of Tx-Rx pair in the following procedure. For each receiver position, find all building information along the direct path between Tx and Rx such as building height, space between buildings, the width of road, and etc. When considering the building height, Tx antenna height, and Rx antenna height, terrain height is included. And when the ITU-R P.1411 model is applied, the relative heights of $h_{m}$ and $h_{b}$ with respect to $h_{r}$, specifically $\Delta h_{m}\left(=h_{r}-h_{m}\right)$ and $\Delta h_{b}\left(=h_{b}-h_{r}\right)$ are used. Then, considering the condition of Eq. (6), path loss components such as $L_{b f}, L_{r t s}, L_{m s d}$, and $L_{k e}$ are computed using obtained building information. Figure 1 shows the building information for a certain $\mathrm{Rx}$ point in the Yeoui-do area and the applied parameter values for prediction are described in Table 1. In Fig. 1, the dotted line is the 1st Fresnel ellipsoid over a path of length $l$ according to the average building height $h_{r}$. The predicted path loss based on $L_{N L o S, 1}$ and $L_{N L o S, 2}$ are $185.17 \mathrm{~dB}$ and $146 \mathrm{~dB}$, respectively. And the measured path loss at this point is $134.5 \mathrm{~dB}$.

The measured and the predicted path losses are shown in Figs. 2(a), 2(b) for about $159 \mathrm{Rx}$ points in the urban type I and in Figs. 2(c), 2(d) for $158 \mathrm{Rx}$ points in the urban type II. $\mathrm{Rx}$ positions are randomly selected through the entire area for both types of environments. As shown in Fig. 1, the path loss is overestimated when only $L_{N L o S, 1}$ is applied because when there is a very tall building between $\mathrm{Tx}$ and $\mathrm{Rx}, L_{r t s}$ has large value due to the effects of the very tall building on

\begin{tabular}{|c|c|c|c|c|c|}
\hline Parameter & $d(\mathrm{~m})$ & $d_{l}(\mathrm{~m})$ & $d_{2}(\mathrm{~m})$ & $h(\mathrm{~m})$ & $v$ \\
\hline Value & 425 & 406.6 & 18.4 & 129.54 & 117.43 \\
\hline
\end{tabular}
the $h_{r}$ and on $\Delta h_{b}$. In other words, there are some low build-

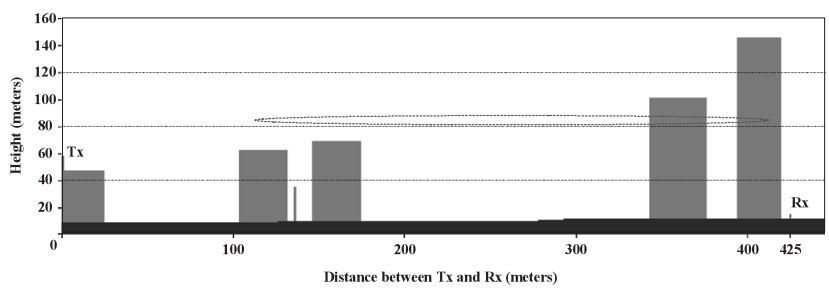

Fig. 1 A building profile between Tx and Rx in Yeoui-do area.

Table 1 The value of applied parameters for prediction.

(a) $L_{N L o S, 1}$ model $\left(=L_{b f}+L_{m s d}+L_{r t s}\right)$

\begin{tabular}{|c|c|c|c|c|c|c|c|c|c|}
\hline $\begin{array}{c}\text { Parame- } \\
\text { ter }\end{array}$ & $d(\mathrm{~m})$ & $w(\mathrm{~m})$ & $\varphi\left(^{\circ}\right)$ & $h_{b}(\mathrm{~m})$ & $h_{r}(\mathrm{~m})$ & $\begin{array}{c}h_{\max } \\
(\mathrm{m})\end{array}$ & $h_{m}(\mathrm{~m})$ & $b(\mathrm{~m})$ & $l(\mathrm{~m})$ \\
\hline Value & 425 & 20 & 72.4 & 57.7 & 83.12 & 146 & 14.6 & 72.5 & 330 \\
\hline
\end{tabular}




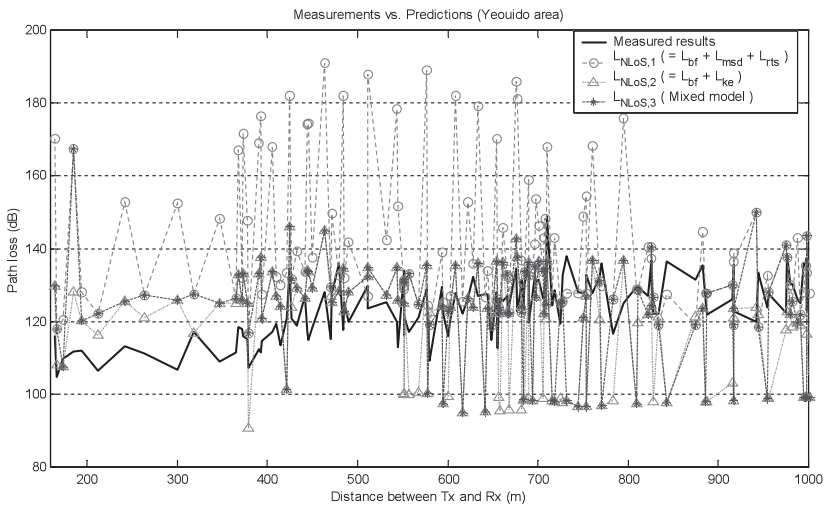

(a) Yeoui-do area $(160-1000 \mathrm{~m})$

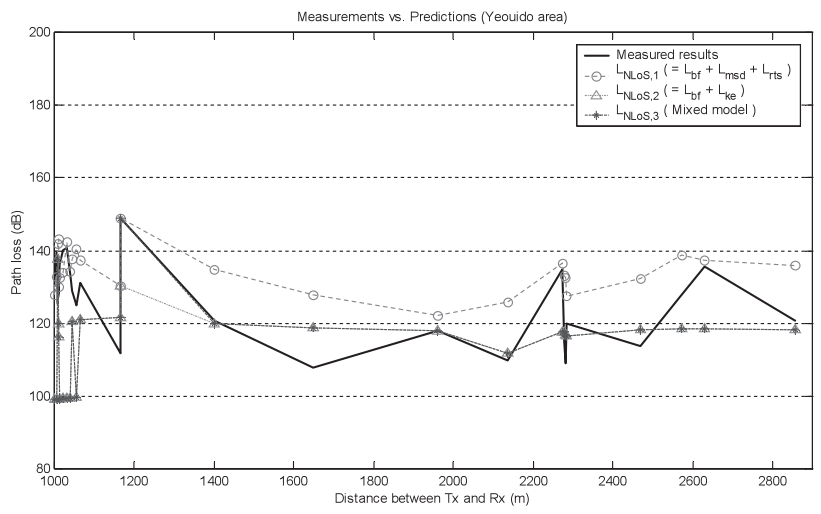

(b) Yeoui-do area (1000-2900 m)

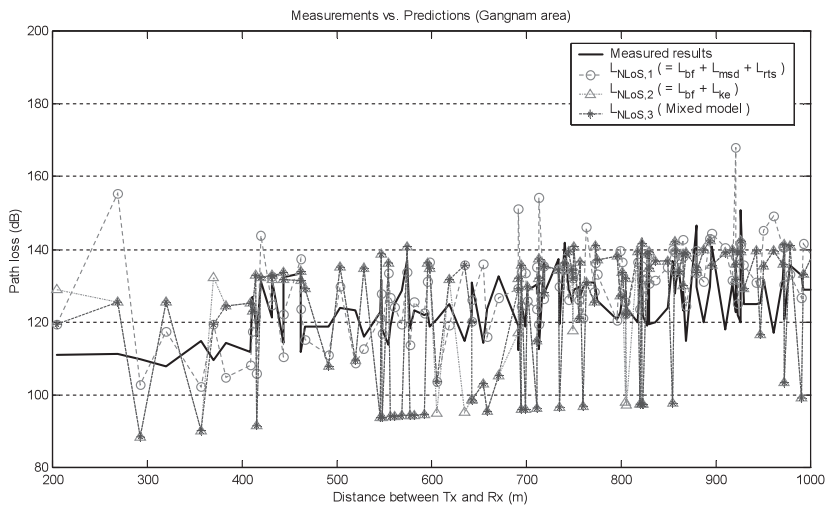

(c) Gangnam area (200-1000 m)

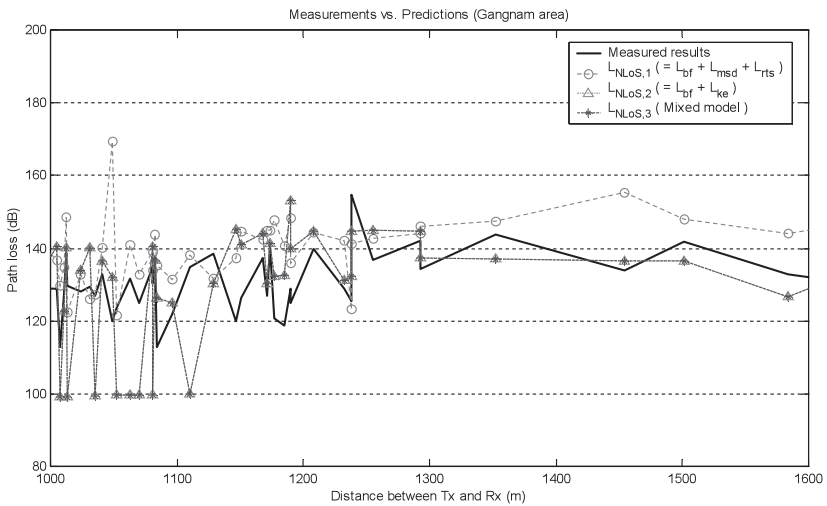

(d) Gangnam area (1000-1600 m)

Fig. 2 Comparison of the measured and predicted path losses using existing prediction model.
Table 2 Statistics of prediction error before corrections.

\begin{tabular}{|c|c|c|c|c|c|}
\hline & & Average & $\begin{array}{c}\text { Standard } \\
\text { deviation }\end{array}$ & Max & Min \\
\hline \multirow{2}{*}{$\begin{array}{c}\text { Yeoui-do } \\
\text { area } \\
\text { (Urban } \\
\text { type I) }\end{array}$} & $\mathrm{L}_{\text {NLoS, 1 }}$ & $-15.1 \mathrm{~dB}$ & $19.1 \mathrm{~dB}$ & $-65.0 \mathrm{~dB}$ & $0.05 \mathrm{~dB}$ \\
\cline { 2 - 6 } & $\mathrm{L}_{N L o S, 2}$ & $7.0 \mathrm{~dB}$ & $17.1 \mathrm{~dB}$ & $-26.3 \mathrm{~dB}$ & $0.04 \mathrm{~dB}$ \\
\cline { 2 - 6 } & $\mathrm{L}_{N L o S, 3}$ & $1.9 \mathrm{~dB}$ & $17.2 \mathrm{~dB}$ & $-55.4 \mathrm{~dB}$ & $0.04 \mathrm{~dB}$ \\
\hline \multirow{2}{*}{$\begin{array}{c}\text { Gangnam } \\
\text { area } \\
\text { (Urban } \\
\text { type II) }\end{array}$} & $\mathrm{L}_{N L o S, 1}$ & $-5.7 \mathrm{~dB}$ & $11.7 \mathrm{~dB}$ & $-49.5 \mathrm{~dB}$ & $0.09 \mathrm{~dB}$ \\
\cline { 2 - 6 } & $\mathrm{L}_{N L o S, 2}$ & $1.5 \mathrm{~dB}$ & $17.0 \mathrm{~dB}$ & $-25.5 \mathrm{~dB}$ & $-0.03 \mathrm{~dB}$ \\
\cline { 2 - 6 } & $\mathrm{L}_{N L o S, 3}$ & $0.8 \mathrm{~dB}$ & $16.5 \mathrm{~dB}$ & $-25.5 \mathrm{~dB}$ & $-0.03 \mathrm{~dB}$ \\
\hline
\end{tabular}

ings and one very tall building in real situation as Fig. 1, but there seem to exist some tall buildings in predicting the path loss based on $L_{N L O S, 1}$. On the other hand, when only $L_{N L o S, 2}$ is applied, the path loss is much underestimated. The reason will be commented in Sect. 4.

The prediction error statistics of the existing model is shown in Table 2.

\section{Correction Factors}

For some Rx positions, the difference between the measured path loss and the predicted path loss with the existing model is excessively large as shown in Fig. 2. Two major reasons for over/underestimation of path loss are identified to develop corresponding correction factors in this paper. For the first reason, when combining $L_{N L o S, 1}$ and $L_{N L o S, 2}$, building height differences between Tx and Rx is only considered. But the relationship between the Tx antenna height and the heights of the buildings existing between Tx and Rx is not considered. When $h_{b}$ is larger than $h_{\max }$, the parameter $h$ of $L_{k e}$ is very small or negative, which leads $L_{k e}$ to be excessively underestimated. But in this case, since all low buildings have effects on the path loss, both the $L_{r t s}$ and $L_{m s d}$ must be considered. When there is only one building between $T x$ and $\mathrm{Rx}$, the path loss must be predicted as the sum of freespace loss with $L_{r t s}$, not $L_{k e}$. Therefore the mixed predicted path loss of Eq. (6) is changed as follows:

$$
L_{N L o S, 3}=\left\{\begin{array}{cc}
L_{N L o S, 1}, & h_{\max } \leq \max \left(h_{r}+R_{1, \max }, h_{b}\right) \\
L_{b f}+L_{r t s}, & \text { only one builing is existed } \\
L_{N L o S, 2}, & \text { else }
\end{array}\right.
$$

For the second reason, predicting the diffraction loss from roof-top of last building to street $L_{r t s}$, only two principal rays were taken into account since other rays have fairly weak power to be neglected [9]. The principal rays are direct-diffracted ray and single-reflected ray by a building across the street. But when Rx is located on the crossroads, more rays having considerable power can reach to $\mathrm{Rx}$ from various directions. In example, those can be singlediffracted ray from the corner of buildings near to $\mathrm{Rx}$ and 


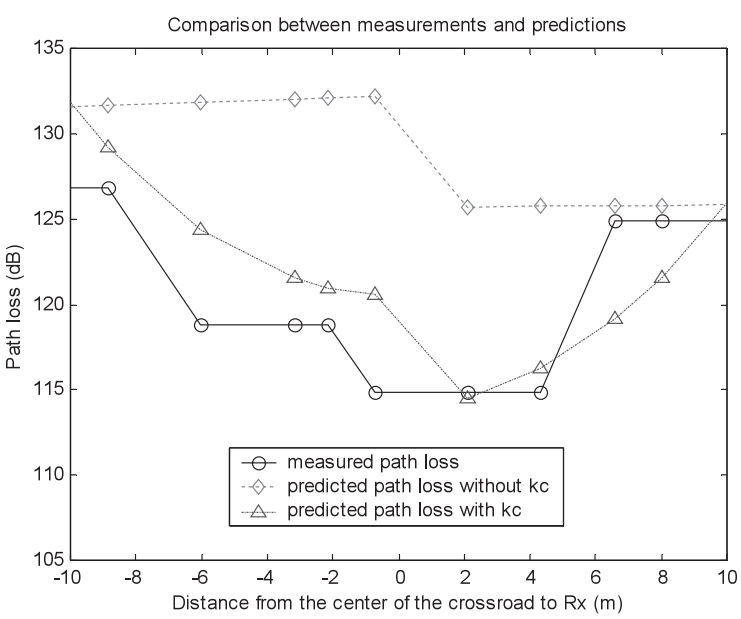

(a) $17 \mathrm{~m} \times 10 \mathrm{~m}$ crossroad. $\left(w_{t}=10 \mathrm{~m}\right)$

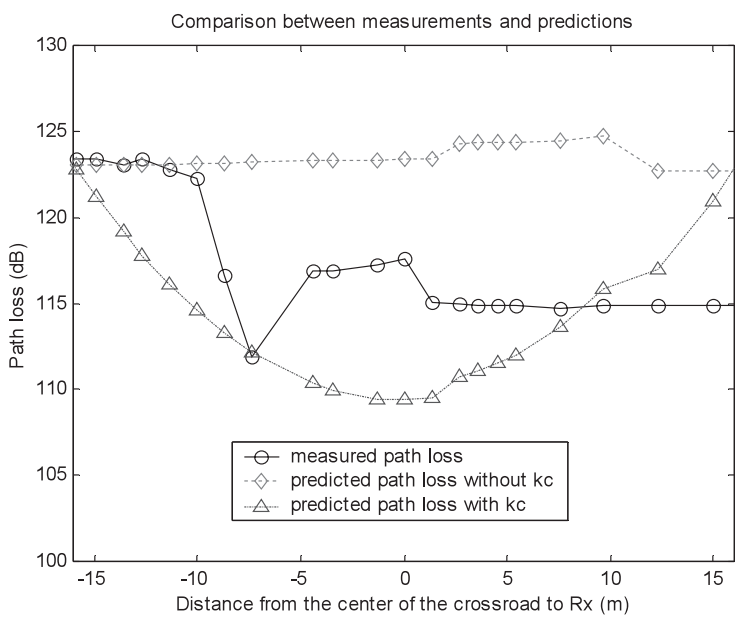

(b) $47 \mathrm{~m} \times 16 \mathrm{~m}$ crossroad. $\left(w_{t}=16 \mathrm{~m}\right)$

Fig. 3 The effect of $k_{c}$.

other single-reflected rays by surrounding buildings. Thus, without considering these rays, the predicted path loss for $\mathrm{Rx}$ on the crossroads would be overestimated. Although the crossroad factor was suggested for the limited environment in the literature [10], the simple empirical crossroad factor $k_{c}(\mathrm{~dB})$ is suggested in this paper based on the difference between predictions and measured results. The measured results for Rx positions around crossroads are used in order to obtain the regression fit equation.

$$
\begin{aligned}
& k_{c}= \begin{cases}\alpha d^{2}+\beta, & -w_{t} \leq d \leq w_{t} \\
0, & \text { elsewhere }\end{cases} \\
& \alpha=-\beta / w_{t}^{2} \\
& \beta=-0.018 \cdot w_{t}^{2}+0.85 \cdot w_{t}+5
\end{aligned}
$$

Where $w_{t}\left(5 \mathrm{~m} \leq w_{t} \leq 45 \mathrm{~m}\right)$ is the width of the transversal street, where the Rx does not travel and $d$ the distance from the center of the crossroad to Rx location, respectively. Figure 3 shows the effect of the correction factor $k_{c}$ for two crossroads.

The prediction errors are reduced a lot after applying the modified prediction model as shown in Fig. 4. And the

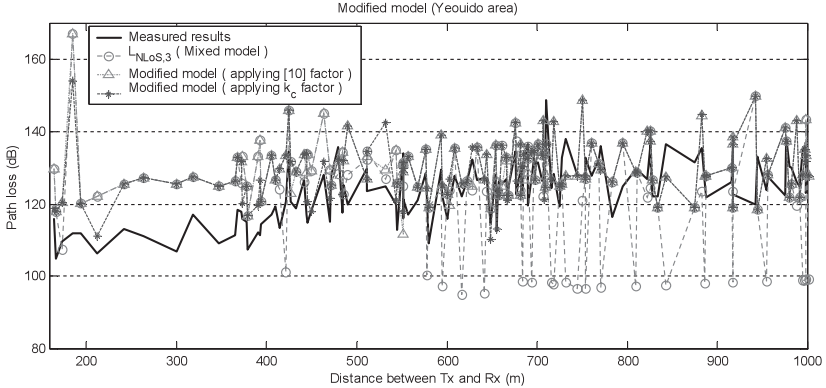

(a) Yeoui-do area. $(160-1000 \mathrm{~m})$

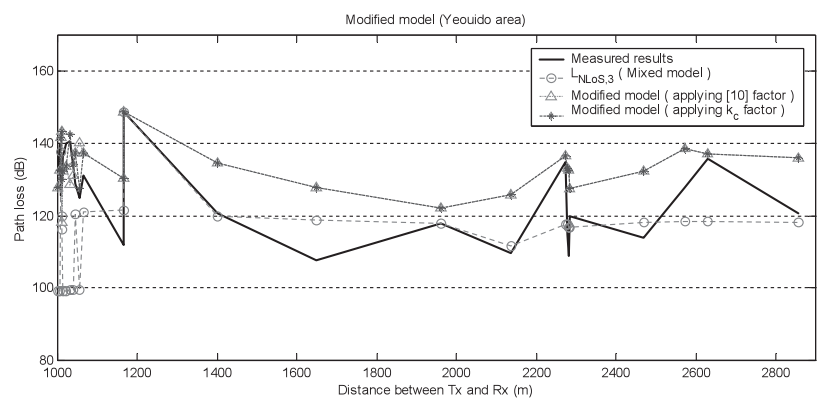

(b) Yeoui-do area. (1000-2900 m)

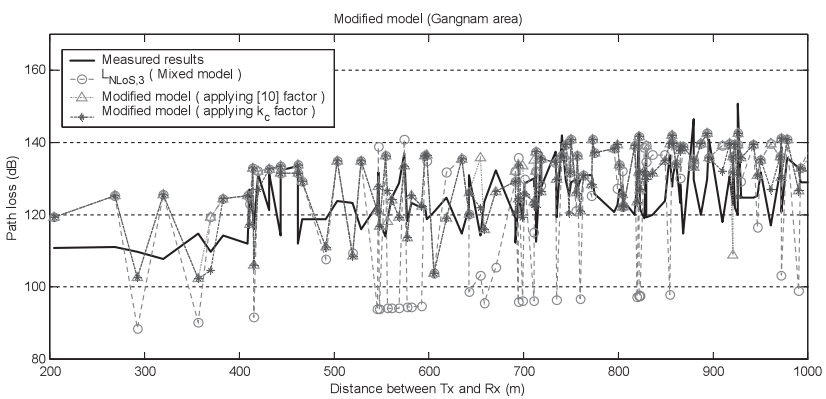

(c) Gangnam area. $(200-1000 \mathrm{~m})$

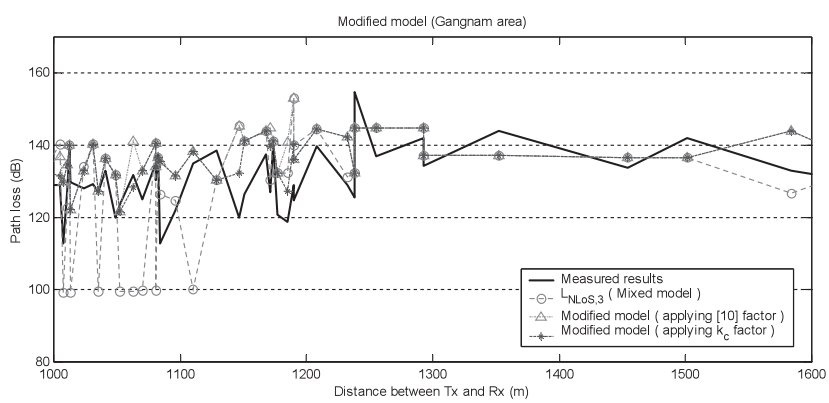

(d) Gangnam area. (1000-1600 m)

Fig. 4 Comparison of the existing and the modified path loss prediction model.

results after applying crossroad factor [10] instead of Eq. (8) are also plotted. Error statistics with the modified model is given in Table 3. Not only the error statistics but also the maximum error is enhanced after applying two correction factors.

After applying the modified model to other Rx locations (about 3000) in the same area, the total average and standard deviation of errors are $-5.36 \mathrm{~dB}$ and $12.4 \mathrm{~dB}$, respectively. 
Table 3 Statistics of prediction error after corrections.

\begin{tabular}{|c|c|c|c|c|c|}
\hline & & Average & $\begin{array}{l}\text { Standard } \\
\text { deviation }\end{array}$ & Max & Min \\
\hline \multirow{3}{*}{$\begin{array}{l}\text { Yeoui-do } \\
\text { area } \\
\text { (Urban } \\
\text { type I) }\end{array}$} & $\begin{array}{c}\text { Only } 1^{\text {st }} \\
\text { correction } \\
\text { factor }\end{array}$ & $-7.3 \mathrm{~dB}$ & $9.5 \mathrm{~dB}$ & $-55.4 \mathrm{~dB}$ & $-0.05 \mathrm{~dB}$ \\
\hline & $\begin{array}{c}\text { Only } 2^{\text {nd }} \\
\text { correction } \\
\text { factor }\end{array}$ & $3.4 \mathrm{~dB}$ & $16.2 \mathrm{~dB}$ & $-42.4 \mathrm{~dB}$ & $0.04 \mathrm{~dB}$ \\
\hline & $\begin{array}{c}\text { Both two } \\
\text { correction } \\
\text { factors }\end{array}$ & $-5.8 \mathrm{~dB}$ & $8.7 \mathrm{~dB}$ & $-42.4 \mathrm{~dB}$ & $-0.05 \mathrm{~dB}$ \\
\hline \multirow{3}{*}{$\begin{array}{c}\text { Gangnam } \\
\text { area } \\
\text { (Urban } \\
\text { type II) }\end{array}$} & $\begin{array}{c}\text { Only } 1^{\text {st }} \\
\text { correction } \\
\text { factor }\end{array}$ & $-5.7 \mathrm{~dB}$ & $9.5 \mathrm{~dB}$ & $-25.5 \mathrm{~dB}$ & $-0.03 \mathrm{~dB}$ \\
\hline & $\begin{array}{c}\text { Only } 2^{\text {nd }} \\
\text { correction } \\
\text { factor }\end{array}$ & $2.0 \mathrm{~dB}$ & $16.4 \mathrm{~dB}$ & $-24.0 \mathrm{~dB}$ & $-0.03 \mathrm{~dB}$ \\
\hline & $\begin{array}{l}\text { Both two } \\
\text { correction } \\
\text { factors }\end{array}$ & $-4.4 \mathrm{~dB}$ & $8.8 \mathrm{~dB}$ & $-24.0 \mathrm{~dB}$ & $-0.03 \mathrm{~dB}$ \\
\hline
\end{tabular}

\section{Conclusion}

In order to deploy wireless communication systems or to analyze the interference by other systems, the prediction of path loss between Tx and Rx is very important. ITUR P.1411 model produces considerable prediction errors for some urban environment, although it works very well for simple urban environments. Therefore two correction factors for ITU-R P.1411 model are suggested to improve prediction accuracy of the path loss in non-uniform urban environment. The errors are improved on the standard deviation by about $8 \mathrm{~dB}$.

\section{Acknowledgments}

This work was supported partly by Brain Korea 21 Project in 2005 and partly by ITRC.

\section{References}

[1] Y. Okumura, E. Ohmori, T. Kawano, and K. Fukuda, "Field strength and its variability in VHF and UHF Land-Mobile Radio Service," Rec. Electron. Commun. Lab., vol.16, pp.825-873, 1968.

[2] M. Hata, "Empirical formula for propagation loss in land mobile radio services," IEEE Trans. Veh. Technol., vol.VT-29, no.3, pp.317325, Aug. 1980.

[3] J.-F. Wagen, "Propagation mechanisms," COST231 TD(96)042-A Truin, Ch. 4, pp.9-16, April 1996.

[4] ITU-R P. 1546, "Method for point-to-area predictions for terrestrial services in the frequency range $30 \mathrm{MHz}$ to $3000 \mathrm{MHz}$," 2001 .

[5] ITU-R P. 1411-3, "Propagation data and prediction methods for the planning of short-range outdoor radio communication systems and radio local area networks in the frequency range $300 \mathrm{MHz}$ to $100 \mathrm{GHz}, " 2005$.

[6] W.C.Y. Lee, Mobile communications engineering, McGraw-Hill, New York, 1982

[7] E. Moriyama, T. Iwama, and T. Saruwatari, "Experimental investigation of $1.5 \mathrm{GHz}, 2.3 \mathrm{GHz}$ and $2.6 \mathrm{GHz}$ band land mobile radio propagation in urban and rural areas," Proc. VTC'89, vol.1, pp.311315.

[8] ITU-R P.526-5, "Propagation by diffraction," 1997.

[9] F. Ikegami, S. Yosida, T. Takeuchi, and M. Umehira, "Propagation factors controlling mean field strength on urban streets," IEEE Trans. Antennas Propag., vol.32, no.8, pp.822-829, Aug. 1984.

[10] A.R. Claro, J.M. Ferreira, and L.M. Correia, "Assessment of a propagation model for crossroads in micro-cells," Proc. VTC'99 Fall, vol.3, pp.1444-1448, 1999. 